\title{
When the Action to Be Performed at the Stage of Retrieval Enacts Memory of Action Verbs
}

\author{
Thibaut Brouillet'ㄹ, Arthur-Henri Michalland ${ }^{2,3,4}$, Sophie Martin², and Denis Brouillet² \\ ${ }^{1}$ CERSM Laboratory (EA 2931), Université Paris-Nanterre, Nanterre, France \\ EPSYLON Laboratory (EA 4556), University Paul Valéry Montpellier 3, France \\ ${ }^{3}$ LIFAM - Laboratoire Innovation, Formes, Architecture, Milieux, Université Montpellier, France \\ ${ }^{4}$ BALlab - Body, Action, Language Laboratory, Rome, Italy
}

\begin{abstract}
According to the embodied approach of language, concepts are grounded in sensorimotor mental states, and when we process language, the brain simulates some of the perceptions and actions that are involved when interacting with real objects. Moreover, several studies have highlighted that cognitive performances are dependent on the overlap between the motor action simulated and the motor action required by the task. On the other hand, in the field of memory, the role of action is under debate. The aim of this work was to show that performing an action at the stage of retrieval influences memory performance in a recognition task (experiment 1) and a cued recall task (experiment 2), even if the participants were never instructed to consider the implied action. The results highlighted an action-based memory effect at the retrieval stage. These findings contribute to the debate about the implication of motor system in action verb processing and its role for memory.
\end{abstract}

Keywords: memory, motor simulation, motor action, action verbs, enactment

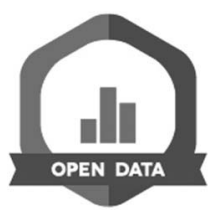

According to the embodied approach of cognition, knowledge relies on the sensorimotor and contextual dimensions of an experience. Moreover, the cognitive system is able to reenact sensorimotor states even in the absence of a stimulus through simulation (Barsalou, 2010).

Regarding embodied approaches of language, a growing number of researches have highlighted that concepts are grounded in sensorimotor mental states. In other words, when we read a word, the process of language comprehension recruits the same perception and action systems that are involved when interacting with real objects represented by the word. Moreover, a significant number of studies have shown a large overlap between the brain areas involved in language and action (for more details, read the following books: Borghi \& Binkofski, 2014; Brouillet, 2019; De Vega et al., 2012; Fincher-Kiefer, 2019; Fischer \& Coello, 2015, 2016; Pecher \& Zwaan, 2005; Shapiro, 2014, 2019). Finally, several researches have shown a bidirectional link between action verb processing and the action performed: Processing an action verb affects action production (Andres et al., 2015; Bidet-Ildei et al., 2017; Boulenger et al., 2009; Glenberg \& Kaschak, 2002; Springer \& Prinz, 2010), and conversely performing an action affects action verb processing (Beauprez \& BidetIldei, 2017; Liepelt et al., 2012). Importantly, Aravena et al. (2010) highlighted the existence of this link at the neuronal level: Action-language comprehension and motor processes thus share neural resources and cooperate.

Although there is a growing body of research supporting the involvement of sensorimotor systems of the brain in the representation of conceptual knowledge, this is still a controversial issue (Dove, 2011; Meteyard et al., 2012; Michel, 2020; Miller et al., 2018; Wurm \& Caramazza, 2019). The debate focuses mostly on the subordination between the sensorimotor system and the conceptual knowledge. If sensorimotor representations can contribute to the conceptual knowledge, it is argued that symbolic representations are necessary to apprehend the broad spectrum of this knowledge (Zwaan, 2016). To this end, Dove (2011, p. 1) suggested that our concepts are represented in at least two ways: (i) through sensorimotor simulations of our interactions with objects and events and (ii) through linguistic representations that are "dis-embodied." That is to say, it involves sensorimotor simulations of experiences that are not associated with its semantic content (p. 6). 
Regardless of this controversy, the role of the sensorimotor system in language is now broadly acknowledged, at least for some conceptual domains, which is not the case regarding memory processes. If the importance of performing an action to recover memories about actions is well documented (for review, see Engelkamp, 1998; Zimmer et al., 2001), the role of action for memory is still debated. For example, Mecklinger et al. (2004) showed that left ventral premotor cortex is activated during maintenance of manipulable objects in working memory. Shebani and Pulvermüller (2013) and Montero-Melis et al. (2019) showed that carrying out a rhythmic task with the hands led to selective impairment of working memory for hand-related words (e.g., clap), while carrying out the same task with the feet led to selective memory impairment for foot-related words (e.g., kick).

However, Pecher et al. (Pecher, 2013; Pecher et al., 2013; Quak et al., 2014), using interference methodology in behavioral studies, failed to highlight the role of motor program in working memory. Nevertheless, Gimenez and Brouillet (2020) showed that the procedure used by Pecher et al. (2013) could be challenged by changing the mode of response and the interference task, which led to an effect of the action performed on working memory.

In the same vein, Pecher et al. failed to replicate previous results showing that participants, in a short-term memory task on action verbs, made more errors when a motor interference task was congruent with the type of action verb than when the motor interference task was noncongruent (for review, see Zeelenberg \& Pecher, 2016). However, Richardson et al. (2001), in a shortterm visual memory task, showed that object affordance is stored at the stage of encoding and can be reactivated during a word recognition task even if the motor components were not involved. In an extension of this work, Brouillet et al. (2015) showed that if the motor components of the objects were perceptually present at the time of recognition, memory judgments were associated with the activation of the motor components of the objects learned.

In long-term memory, the results are also debated. Canits et al. (2018) investigated the influence of compatibility between the typical grasp size of an object and response grasp type on semantic categorization, on delayed free recall, and on a recognition memory task. In the categorization task, the compatibility effect was present, but it was not observed in the long-term memory tasks. These findings contrast with those of van Dam et al. (2013). In their study, participants performed an action between the learning and retrieval phases that was compatible with some learned objects (twist for paper mill, or press for doorbell) and incompatible with other learned objects (twist for piano or press for screw driver). They found that participants' retrieval performance was better in the compatible conditions than incompatible conditions. The results obtained by Dutriaux et al. (2019) also contrast with those of Canits et al. (2018). In their study, participants' hand posture was manipulated to interfere with motor simulation during language processing. In a learning phase, participants were exposed to object-verb sentences (e.g., action sentences: "to take a cup" vs. attentional sentences: "to see a cup") while holding their hands behind their back or in front of them. Results showed that the "hand in the back" posture interfered with recall of object nouns when nouns appeared in the context of action sentences, and not when they appeared in the context of attentional sentences. Brouillet et al. (2018) also showed an effect of motor resonance in long-term memory: They observed, in a categorization task, that when right-oriented tools were primed by an injured hand, response times with the right hand were slower than when the prime was a healthy hand. This response delay was accentuated in a handgrip condition. According to them, these results support the idea that participants activated the corresponding motor program and the pain associated with the consequences of the simulated grasping action.

In addition to those studies, other findings showed that the neural structures governing the selection and execution of actions are activated when participants have to process verbs that represent these actions (Mecklinger et al., 2004; Pulvermüller \& Fadiga, 2010; Pulvermüller et al., 2005; van Elk et al., 2010; Willems et al., 2010, 2011). Recently, Vitale et al. (2020) used transcranial direct current stimulation to test whether exogenous excitatory manipulation of the left primary motor cortex (M1) would improve memory performance with action sentences rather than with attention sentences (as in Dutriaux et al., 2019). Results showed strong evidence of a causal link between the activation of the motor system and memory for action sentences.

In sum, all these studies suggest a role of sensorimotor processes in memory activity. This idea is at the core of multiple traces memory models (e.g., MINERVA 2 - Hintzman, 1984, 1988; VISA - Whittlesea, 1989; ActIn - Versace et al., 2014; ATHENA - Briglia et al., 2018). In these models, the memory system stores the experiences of our interactions with the environment (i.e., episodic traces) in a multisensory and distributed way over the entire brain. In that sense, the content of new memory traces is closely related to former sensorimotor activities. Moreover, in these models, accessing a knowledge is the result of a coupling between the recovery situation and the set of activated episodic traces, and this activation depends on their similarities with the recovery situation, which is called the synergistic ecphory process (Tulving, 1976, 1982). In that sense, knowledge emerges when, in the current situation, there are cues that share various components of the memory traces, such as motor 
components (Brouillet \& Versace, 2019). The aim of the present work was to test this assumption through the use of action verbs. Indeed, due to the role of sensorimotor processes in the processing and acquisition of action verbs, the sensorimotor system should be active also at the time of retrieval in a memory task.

To test this assumption, we carried out two experiments in which the participants had to perform an action to give their answer: The first was a recognition task, and the second a cue recall task. We supposed that the motor components of the action performed to give the responses should work as cues, even if participants were not instructed to consider the implied action. Therefore, our hypothesis is that when the action performed is consistent with the action associated with the verb, memory performance will be enhanced in various retrieval context: recognition and cued recall.

\section{Experiment 1}

The aim of this experiment was to show that performing an action congruent with action verbs increases participants' performance in a recognition task, even when participants are not instructed to consider the action. We also predict that action verbs should be less recognized with an inconsistent action and that memory performance will be higher with a consistent action than with a neutral gesture (i.e., pressing a key).

As the action verbs used involve action toward or away from the body, we expect that action verbs involving a movement away from the body will be more easily and more quickly recognized when the participant has to perform an action away rather than toward the body. We expect the opposite pattern of performance for action verbs involving a movement toward the body. In other words, we expected an interaction between the movement associated with the verbs and the action performed to provide the response.

\section{Method}

\section{Participants}

Ninety students $\left(M_{\text {age }}=21.3, S D=1.65\right)$ from the Department of Psychology at the University of Montpellier, France, and Nice, Italy, took part in this experiment for extra course credit. All participants were French-native speakers and right-handed. Their vision was normal or corrected to normal. All participants gave their informed consent to take part in this experiment and signed the Laboratory's Charter of Ethics. We checked post hoc power analysis with $G^{*}$ Power software (Faul et al., 2007): For an effect size of 0.25 , a probability of .05 and a total sample size of $90, G^{*}$ Power indicates a power of 0.99 .

\section{Material}

We selected 60 action verbs from Duscherer and Mounoud's (2006) French norm. In a pre-experiment, the type of action associated with each verb and the certainty of the judgment made $(1=$ uncertain to $6=$ absolutely certain) was tested with 50 other subjects. The verb selection criteria used were a consensus between participants greater than $80 \%$ on the action associated with the verb and a mean response certainty score greater than 4 . These constraints allowed us to obtain 16 verbs associated with an action involving a movement away from the body (e.g., throw, push, and pour) and 16 verbs associated with an action involving a motion toward the body (e.g., pull, extract, and raise). The characteristics of the 32 verbs selected are shown in the Appendix. The verbs were presented in Times New Roman size 20 in black on a white screen.

\section{Procedure}

Participants were randomly assigned to one of three groups (see the section test phase) and tested individually. The experiment was performed on a Pentium IV computer with a 17-in monitor, using E-Prime software (Schneider et al., 2012). Participants were seated at a table in front of the computer screen, and the screen was set at a distance of about $60 \mathrm{~cm}$ from the participants' eyes. For one group of participants, a keyboard was placed on the table, $50 \mathrm{~cm}$ away from the seat, so that they could rest their forearms on the table. For the two other groups of participants, a lever was placed on the right-hand side (we used a similar material as in Brouillet et al., 2010). This lever had to be either pushed or pulled to provide a response.

\section{Learning Phase}

In the learning phase, participants were instructed to remember the verbs that they were about to see for later recognition. Sixteen action verbs were then presented on the computer screen: Eight verbs were associated with movement away from the body, and eight others with a movement toward the body. On each trial, a fixation cross was presented in the center of the white screen for $500 \mathrm{~ms}$. Then, a verb appeared in the center of the screen for $300 \mathrm{~ms}$, and a white screen was presented for $500 \mathrm{~ms}$ before the beginning of the next trial. The order of the verbs was randomized.

\section{Test Phase}

In the test phase, 32 verbs were presented: the 16 verbs from the learning phase - namely, the "old" verbs - and 16 others that were not presented during the learning phase - namely, the "new" verbs. The new verbs included eight verbs associated with a movement away from the body, and eight verbs associated with a movement toward 
the body. For each trial, a fixation cross was presented in the center of the gray screen for 500 ms. Just after the cross disappeared, the verbs appeared in the center of the screen until participants gave their response. After their response, a blank screen was presented for $500 \mathrm{~ms}$ before the beginning of a new trial. To avoid a potential effect of the verb, the old verbs for a participant became the new ones for another, and reciprocally, the new verbs for a participant became the old ones for another. The order of presentation of the verbs was randomized between participants.

Participants were asked to indicate if the verbs presented were previously in the learning list. $^{1}$ To respond, the first group of 30 participants had to use the index finger of their right hand to press the correct key on the keyboard (called "press" group). After each answer, participants were asked to put their forefinger back on the white key, which was located between the "yes" (indicating that the participants recognized the word as previously presented during the learning phase) and the "no" keys (i.e., the "yes" key corresponded to "V," the "no" key to "N," and the white key to " $\mathrm{B}$ "). The positions of the "yes" and "no" keys were counterbalanced between participants.

In the second and third groups, participants had to push or to pull the lever with their right hand. The second group of 30 participants had to push the lever to answer "yes" and pull it to answer "no" (called "“push" group). After each answer, participants were asked to place the lever back in the middle position, which was indicated by a sound click. The third group of 30 participants had to push the lever to answer "no" and pull it to answer "yes" (called "pull" group). Participants were told to respond as quickly and accurately as possible. The test phase took place about 3 min after the end of the learning phase, which was the time needed to read the instructions.

In summary, there were three sources of variation:

1. nature of the verbs (i.e., old vs. new) manipulated within participants,

2. verb category (i.e., away from the body vs. toward the body) manipulated within participants, and

3. response mode (i.e., press, push, and pull) manipulated between participants.

Analysis was conducted on the "yes" response.

\section{Results}

Statistics were carried out using JASP software (Wagenmakers, Love, et al., 2018; Wagenmakers, Marsman et al., 2018). We performed frequentist repeated-measures ANOVA followed by a Bayesian repeated-measures ANOVA with the category of verbs (i.e., away vs. toward) and nature of verbs (i.e., old vs. new) as a within-participant factor and the mode of response (i.e., pull, push, and press) as a betweenparticipant factor. The Bayes factor $\left(\mathrm{BF}_{10}\right)$ is the ratio of $p(\mathrm{D} \mid \mathrm{H} 1)$, the probability of observing the data under the alternative hypothesis, and $p(\mathrm{D} \mid \mathrm{HO})$, the probability of observing the data under the null hypothesis. So, the Bayes factor is a measure of the probability that the data match the alternative hypothesis rather than the null hypothesis (Rouder et al., 2009). In accordance with the recommendations from Schönbrodt and Wagenmakers (2018), a $\mathrm{BF}_{10} \geq 10$ will be interpreted as strong evidence for the alternative hypothesis, $3 \leq \mathrm{BF}_{10}<10$ as moderate evidence for the alternative hypothesis, and $\mathrm{BF}_{10}<3$ as anecdotal evidence for the alternative hypothesis, with a $\mathrm{BF}_{10}$ close to 1 considered as no evidence.

\section{Responses Analysis}

The mean number of "yes" responses (Table 1) was calculated across participants for each experimental condition (i.e., nature and category of the verbs) and for each group (i.e., pull, push, and press). Note that answering "yes" to "old" verbs is an adequate answer (HIT: signal present and subject says "yes") while answering "yes" to "new" verbs is an incorrect answer (FA, False Alarm: signal absent and subject says "yes"). The notation HIT

Table 1. Mean number of "Yes" responses (max. 8) for old (i.e., HIT) and new (i.e., FA) items according to verb category (toward vs. away from the body) and mode of response (pull, push, or press)

\begin{tabular}{llllll}
\hline & \multicolumn{2}{c}{ Old (HIT) } & & \multicolumn{2}{c}{ New (FA) } \\
\cline { 2 - 3 } \cline { 6 - 6 } & Toward & Away & & Toward & Away \\
\hline Pull & $7.06(0.86)$ & $4.23(1.13)$ & & $4.23(1.07)$ & $0.96(0.80)$ \\
Push & $4.20(1.18)$ & $6.96(0.99)$ & & $1.00(0.87)$ & $3.96(1.12)$ \\
Press & $5.66(0.99)$ & $5.86(1.43)$ & & $1.63(0.99)$ & $1.86(0.86)$ \\
\hline
\end{tabular}

Note. SEs are presented in brackets.

\footnotetext{
The instruction was, "You will see a verb appearing in the center of the screen. You will have to say if this verb was present or not in the learning phase. The verb will remain displayed until you have given your answer" (common to all groups). "To do this, you have to tap the "yes" key or the "no" key with your forefinger of your right hand. Once you have given your answer you have to put it on the white key" (group "press"). "To do this, you have to touch the "yes" switch or the "no" switch with the lever. You must move the lever with your right hand. Once you have given the answer you must move the lever back to the center. You will hear a click at this point" ("pull" and "push" groups).
} 
and FA is the one used in signal detection theory (see below). We ran ANOVAs with the nature of the items (i.e., old vs. new) and verb category (i.e., away vs. toward verbs) as within-participant factors, and the mode of response (i.e., pull, push, and press) as a between-participant factor.

The three-way interaction (Nature of the verbs $\times$ Verb category $\times$ Response mode) was not significant, $F(2,87)=$ $0.73, p=.48, \eta_{\mathrm{p}}^{2}=.0004, \mathrm{BF}_{10}=0.07$. The interaction between the mode of response and the nature of the items was significant, $F(2,87)=7.96, p<.01, \eta_{\mathrm{p}}^{2}=.15=.15, \mathrm{BF}_{10}=$ $2.17^{+56}$, as the interaction between the mode of response and the verb category, $F(2,87)=256.19, p<.01, \eta_{\mathrm{p}}^{2}=.85$, $\mathrm{BF}_{10}=8.39^{+19}$.

The analysis revealed a significant main effect of response mode, $F(2,87)=3.86, p<.05, \eta_{\mathrm{p}}^{2}=.08, \mathrm{BF}_{10}=0.06$. Participants produced more "yes" responses (i.e., average HIT + FA) when performing an action with the lever compared to pressing a key on the keyboard, $F(1,87)=7.28, p<$ $.01, \eta_{\mathrm{p}}^{2}=.1, \mathrm{BF}_{10}=5.07$. However, there was no difference between the "push" group and the "pull" group, $F<1$.

The analysis showed no effect of verb category, $F(1$, $87)=0.01, p=.91$. Verbs "toward" were as well recognized as verbs "away."

The analysis revealed a classic effect of the nature of the items, $F(1,87)=925.94, p<.01, \eta_{\mathrm{p}}^{2}=.91, \mathrm{BF}_{10}=1.29^{+57}$. The old verbs were more rated as old than the new verbs for each response mode and each category of verbs (Table 2). So, we will first present the results for the old words and then for the new words (the Holm-Bonferroni correction is applied on partial analysis).

\section{Old Verbs}

The interaction "Nature of the verbs $\times$ Mode of response" was significant, $F(2,87)=96.59, p<.001, \eta_{\mathrm{p}}^{2}=.68, \mathrm{BF}_{10}=$ $1.52^{+26}$. However, neither the factor "nature of the verbs," $F(1,87)=0.07, p=.78$, nor the factor "mode of response" was significant, $F(2,87)=0.40, p=.66, \eta_{\mathrm{p}}^{2}=.009$. The comparisons (Table 3 ) showed that (a) for verbs "toward," pulling responses improved correct recognitions compared to pushing and pressing responses, and pushing responses reduced correct recognitions compared to pressing; (b) for

Table 2. Comparisons of old vs. new according to the nature of the verbs (toward and away) and to the mode of response (pulling, pushing, and pressing)

\begin{tabular}{lcc}
\hline & Verbs toward & Verbs away \\
\hline Pulling & $t(29)=11.79$, & $t(29)=12.5$, \\
& $p_{\text {holm }}<.001, \eta_{p}^{2}=.70$ & $P_{\text {holm }}<.001 \eta_{p}^{2}=.72$ \\
Pushing & $t(29)=10.91$, & $t(29)=10.57$, \\
& $p_{\text {holm }}<.001, \eta_{p}^{2}=.67$ & $P_{\text {holm }}<.001, \eta_{p}^{2}=.65$ \\
Pressing & $t(29)=19.56$, & $t(29)=12.16$, \\
& $P_{\text {holm }}<.001, \eta_{p}^{2}=.86$ & $P_{\text {holm }}<.001, \eta_{p}^{2}=.71$ \\
\hline
\end{tabular}

Table 3. Statistics according to the nature of the verbs (toward and away) and to the mode of response (pulling, pushing, and pressing)

\begin{tabular}{lcc}
\hline & Verbs toward & Verbs away \\
\hline Press-pull & $t(58)=4.85$, & $t(58)=5.66$, \\
& $P_{\text {holm }}<.001, \eta_{p}^{2}=.28$ & $P_{\text {holm }}<.001, \eta_{p}^{2}=.35$ \\
Press-push & $t(58)=5.08$, & $t(58)=3.81$, \\
& $P_{\text {holm }}<.001, \eta_{p}^{2}=.30$ & $P_{\text {holm }}<.001, \eta_{p}^{2}=.20$ \\
Pull-push & $t(58)=9.93$, & $t(58)=9.47$, \\
& $P_{\text {holm }}<.001, \eta_{p}^{2}=.62$ & $P_{\text {holm }}<.001, \eta_{p}^{2}=.60$ \\
\hline
\end{tabular}

verbs "away," pushing responses improved correct recognitions compared to pulling and pressing responses, and pulling reduced correct recognitions compared to pressing.

\section{New Verbs}

The interaction "Nature of the verbs $\times$ Mode of response" was significant, $F(2,87)=161.06, p<.001, \eta_{\mathrm{p}}^{2}=.78, \mathrm{BF}_{10}=$ $3 \times 10^{+19}$. The factor "nature of the verbs" was not significant, $F(1,87)=0.02, p=.87$. But the factor "mode of response" was significant, $F(2,87)=13.09, p<.001, \eta_{\mathrm{p}}^{2}=.23$. The comparison showed that less false recognitions were made in the "press" group, compared to the "pull" group, $t(58)=4.72$, pholm $<.001$, and to the "push" group, $t(58)=$ $4.07, p_{\text {holm }}<.001$. There was no difference between the "pull" and "push" groups, $t(58)=0.64, p_{\text {holm }}=.51$.

The post hoc analysis of the interaction (Table 4) showed that (a) for verbs "toward," pulling responses increased false recognitions compared to pushing and pressing responses, and pushing reduced false recognitions compared to pressing; (b) for verbs "away," pushing responses increased false recognitions compared to pulling and pressing responses, and pulling reduced false recognitions compared to pressing.

\section{Discrimination Accuracy}

According to the accuracy-oriented approach (for review, see Koriat et al., 2000), memory performance does not depend only on the probability of recovering a mere event but also on reconstructing an event or an experience corresponding to the environmental constraints (i.e., constraint of the task, nature, and richness of the cue, fluency misattribution). In other words, memory accuracy

Table 4. Statistics according to the nature of the verbs (toward and away) and to the mode of response ("pull," "push," and "press" groups)

\begin{tabular}{lcc}
\hline & Verbs toward & Verbs away \\
\hline Press-pull & $t(58)=10.38$, & $t(58)=3.59$, \\
& $p_{\text {holm }}<.001, \eta_{p}^{2}=.65$ & $P_{\text {holm }}=.003, \eta_{p}^{2}=.18$ \\
Press-push & $t(58)=2.52$, & $t(58)=8.38$, \\
& $p_{\text {holm }}=.04, \eta_{p}^{2}=.09$ & $P_{\text {holm }}<.001, \eta_{p}^{2}=.54$ \\
Pull-push & $t(58)=12.90$, & $t(58)=11.97$, \\
& $P_{\text {holm }}<.001, \eta_{p}^{2}=.74$ & $P_{\text {holm }}<.001, \eta_{p}^{2}=.71$ \\
\hline
\end{tabular}


preferentially refers to the ratio between the probability for the memory systems to produce an adequate response (HIT) and the probability to produce an inadequate response (FA). The Signal Detection Theory (Green \& Swets, 1966) provides a model to measure participants' discrimination accuracy in terms of the distance between the means of the target and lure response distribution, and this distance is called $d^{\prime}\left(d^{\prime}=z(\mathrm{FA})-z(\mathrm{H})\right)$. In other words, the calculation of $d^{\prime}$ allowed us to know the ability of the subject to distinguished old words (i.e., targets) from new words (i.e., lures). Specifically, the higher the $d^{\prime}$ value, the more the subject was able to discriminate old from new words, while the lower the $d^{\prime}$ value, the lesser the subject was able to distinguish them.

The proportions of responses were calculated for each condition for each participant. Hits (responses "yes" to old words) and false alarms (responses "yes" to new words) were used to calculate $d^{\prime}$ values. We replaced scores of 0 by $0.5 /$ total and scores of 1 by (total -0.5 )/total, where total was the total number of items in the condition (Quak et al., 2014). Table 5 shows mean average $d^{\prime}$ values.

The interaction between response mode and category of verbs was significant, $F(2,87)=3.86, p=.02, \eta_{\mathrm{p}}^{2}=.08$, $\mathrm{BF}_{10}=2.25^{+4}$. No effect of verb category was observed, $F(1,87)=0.09, p=.76, \eta_{\mathrm{p}}^{2}=.001, \mathrm{BF}_{10}=0.16$. The analysis also revealed a significant main effect of response mode, $F(2,87)=20.85, p<.001, \eta_{\mathrm{p}}^{2}=.31 ; \mathrm{BF}_{10}=4.24^{+4}$. Participants better discriminated old and new verbs when they pressed the keyboard than when they moved the lever: "pull" vs. "press" group, $t(58)=5.45, p_{\text {holm }}<.001$, $\eta_{\mathrm{p}}^{2}=.33$; "push" vs. "press" group, $t(58)=5.51, p_{\text {holm }}<$ $.001, \eta_{\mathrm{p}}^{2}=.34$. The difference between "push" and "pull" groups was not significant, $t(58)=.06, p_{\text {holm }}=.95$.

The post hoc analysis of the interaction (Table 6) showed that regardless of the verb category, participants' discrimination performance between old and new verbs were better in the "press" than "pull" and "push" groups, but the difference between "push" and "pull" groups was not significant.

\section{Response Times}

The response times for the "press" group were not included in the analysis as the required action was not

Table 5. Mean average $d^{\prime}$ according to the response mode (pulling, pushing, and pressing) and the category of verbs (toward and away)

\begin{tabular}{lcc}
\hline & Toward & Away \\
\hline Pull & $0.42(0.60)$ & $0.78(0.71)$ \\
Push & $0.72(0.64)$ & $0.46(0.48)$ \\
Press & $1.24(0.55)$ & $1.22(0.68)$ \\
\hline
\end{tabular}

SEs are presented in brackets.
Table 6. Statistics according to the nature of the verbs (toward and away) and to the mode of response (pulling, pushing, and pressing)

\begin{tabular}{ccc}
\hline & Verbs toward & Verbs away \\
\hline Press-pull & $t(58)=5.09$, & $t(58)=2.78$, \\
& $p_{\text {holm }}<.001, \eta_{p}^{2}=.30$ & $p_{\text {holm }}=.048, \eta_{p}^{2}=.11$ \\
Press-push & $t(58)=3.23$, & $t(58)=4.73$, \\
& $p_{\text {holm }}=.016, \eta_{\mathrm{p}}^{2}=.15$ & $p_{\text {holm }}<.001, \eta_{p}^{2}=.27$ \\
Pull-push & $t(58)=1.86$, & $t(58)=1.95$, \\
& $p_{\text {holm }}=.32, \eta_{p}^{2}=.05$ & $p_{\text {holm }}=.315, \eta_{p}^{2}=.06$ \\
\hline
\end{tabular}

comparable to the response in the "push" and "pull" groups. In situations requiring pushing or pulling, the range of motion is greater than in situations requiring pressing, and therefore induce longer response times. In the "press" group, the mean response time for old items was $494.56 \mathrm{~ms}$ for toward verbs and $492.01 \mathrm{~ms}$ for away verbs. For new items, the mean response time was $569.80 \mathrm{~ms}$ for toward verbs and $588.31 \mathrm{~ms}$ for away verbs. The difference between these two categories of verbs was not significant $(F<1)$.

We conducted analyses of response times only for old items (Table 7). Indeed, for the new items, 12 participants in the "pull" group did not make false recognitions (FA) for verbs away and 9 participants of the "push" group did not make false recognitions for verbs toward.

For old verbs, analysis showed no effect of response mode, $F(1,58)=1.33, p=.25, \eta_{\mathrm{p}}^{2}=.02, \mathrm{BF}_{10}=0.32$, and no effect of verb category, $F(1,58)=0.23, p=.62, \eta_{\mathrm{p}}^{2}=.004$, $\mathrm{BF}_{10}=0.20$. However, the analysis revealed a significant interaction between mode of response and verb category, $F(1,58)=26.21, p<.01, \eta_{\mathrm{p}}^{2}=.31, \mathrm{BF}_{10}=5,637.13$. The comparisons showed that pulling for verbs toward induced faster response times than pushing, $t(58)=4.45$, $p_{\text {holm }}<.001, \eta_{\mathrm{p}}^{2}=.25$, and the pulling for verbs away induced slower response times than pushing, $t(58)=2.83$, $p_{\text {holm }}=.01, \eta_{\mathrm{p}}^{2}=.12$.

\section{Conclusion}

Our results showed a robust effect of overlapping between the movement associated with a verb and the action performed to render a memory judgment on that verb,

Table 7. Mean RT (in ms) for old (i.e., HIT) for "old" responses according to verb category (toward vs. away from the body) and mode of response (pull vs. push)

\begin{tabular}{lcr}
\hline & \multicolumn{2}{c}{ Old (HIT) } \\
\cline { 2 - 3 } & Toward & \multicolumn{1}{c}{ Away } \\
\hline Pull & $516.91(102.42)$ & $621.71(123.82)$ \\
Push & $658.43(145.76)$ & $531.69(115.70)$ \\
\hline
\end{tabular}

SEs are presented in brackets. 
even if the participants were not instructed to pay attention to the action performed to answer. Participants considered verbs as old items more often when congruent consistent action was required to produce the judgment: push for verbs away and pull for verbs toward, and the opposite pattern appeared with inconsistent actions: push for verbs toward and pull for verbs away. The analyses of the recognition times confirmed this overlapping effect: participants recognized more rapidly the verbs "toward" when they had to pull to respond "yes" than to push. The same was true for the verbs "away" when they had to push to respond "yes" than to pull. Finally, the ease, indicated by d' values, in discriminating new verbs from old verbs when the action to produce the judgment was congruent with the action suggested by the verbs reinforces the idea that the action performed to answer and the action linked with the verb resonate.

\section{Experiment 2}

The aim of this second experiment was to replicate the findings of the first experiment in a cued recall task. We expected that the recall rate would depend on the action performed: After a pushing action, participants' performance at recalling action verbs from the "away" category should be better; after a pulling action, participants should recall more verbs from the "toward" category; and after a pressing action, participants should recall "away" verbs and "toward" verbs in similar proportions.

\section{Method}

\section{Participants}

Sixty students $\left(M_{\mathrm{age}}=20.6, S D=1.92\right)$ from the Department of Psychology at the University of Montpellier who did not participate in Experiment 1 took part in this experiment for extra course credit. All participants were French-native speakers and right-handed. Their vision was normal or corrected to normal. All participants gave their informed consent to take part in this experiment and signed the Laboratory's Charter of Ethics. We checked post hoc power analysis with $G^{*}$ Power software (Faul et al.,
2007): For an effect size of 0.25 , a probability of .05, and a sample size of $60, G^{*}$ Power indicates a power of 0.93 .

\section{Material}

We used 20 verbs from Experiment 1: 10 verbs associated with an action involving a movement away from the body (i.e., "away"), and 10 verbs associated with an action involving a motion toward the body (i.e., "toward"). The verbs were presented in Times New Roman size 20 in black on a white screen.

\section{Procedure}

The procedure was the same as Experiment 1 except that 20 action verbs were presented instead of 32 , and the test phase consisted of a recall task.

\section{Test Phase}

Participants were asked to recall the verbs from the learning phase, irrespective of their order. A question mark appeared on the computer screen, and participants had to press a key ("press" group, 20 participants), pull a lever ("pull" group, 20 participants), or push it (push group, 20 participants) to make the question mark disappear. As soon as the question mark disappeared, participants had to recall one verb. ${ }^{2}$ It was stated that performing the action allowed them to produce verbs at their own rhythm.

The test phase took place about 5 min after the learning phase, which was the time needed to read the instructions and to learn how to use the response device to make the question mark disappear (six trials without recall were performed by the participants).

\section{Results}

The mean number of words recalled was calculated for each participant for each experimental condition (i.e., verbs) and for each group (i.e., pull, push, and press). We distinguished (Table 8) the verbs correctly recalled (i.e., present in the learning phase) from those falsely recalled (i.e., not present in the learning phase). For verbs falsely recalled, we distinguished between verbs that evoke an action away from the body (i.e., "away"), from those that evoke an action toward the body (i.e., "toward"), and from verbs that do not evoke one of these two actions (i.e.,

\footnotetext{
2 The instruction was, "You will have to recall the verbs you have learned regardless of the order in which they were learned." To allow your answer to be recorded, "you will have to produce the verbs you remember once you have removed the question mark displayed on the screen" (common to all groups). "To remove the question mark, you must press the space bar with the forefinger of your right hand" ("press" group). "To remove the question mark, you must move the lever with your right hand to the switch (group "pull" and "push"). Before you start, you will have to remove the question mark six times to familiarize with the device" (common to all groups).
} 
Table 8. Mean number of items correctly recalled (max. 8) for old (i.e., HIT) and incorrectly recalled according to verb category (toward vs. away from the body) and mode of response (pull, push, or press)

\begin{tabular}{lcclll}
\hline & \multicolumn{2}{c}{ Correct } & & \multicolumn{2}{c}{ Incorrect } \\
\cline { 2 - 3 } \cline { 6 - 6 } & Toward & Away & & Toward & Away \\
\hline Pull & $6.85(0.57)$ & $3.95(0.32)$ & & $1.05(0.04)$ & $0.20(0.01)$ \\
Push & $3.70(0.30)$ & $6.75(0.56)$ & & $0.15(0.01)$ & $0.90(0.07)$ \\
Press & $4.90(0.40)$ & $5.00(0.41)$ & & $0.10(0.08)$ & $0.15(0.01)$ \\
\hline
\end{tabular}

SEs are presented in brackets.

"others"). To do this, the classification was carried out by three independent judges.

We ran two distinct repeated-measures ANOVAs followed a Bayesian repeated-measures ANOVA on the number of words correctly recalled and the number of words falsely recalled, with the category of verbs (i.e., away vs. toward verbs) as a within-participant factor and the mode of response (i.e., pull, push, and press) as a between-participant factor.

\section{Verbs Correctly Recalled}

The analysis revealed no main effect of action, $F(2,57)=$ $1.44, p=.24, \eta_{\mathrm{p}}^{2}=.04, \mathrm{BF}_{10}=0.15$, nor effect of verb category, $F(1,57)=0.20, p=.65, \eta_{\mathrm{p}}^{2}=.0034, \mathrm{BF}_{10}=0.20$. However, there was a significant interaction between the mode of response and the verbs, $F(2,57)=86.57, p<.01$, $\eta_{\mathrm{p}}^{2}=.75, \mathrm{BF}_{10}=6.89^{+19}$. The comparisons (Table 9) showed that (a) for verbs "toward," the pulling mode of response increased the number of items correctly recalled compared to pushing and pressing, and the pushing mode of response reduced the number of items correctly recalled compared to pressing; (b) for verbs "away," pushing increased correct recalls compared to pulling and pressing, and pulling reduced correct recalls compared to pressing.

\section{Verbs Falsely Recalled}

The interaction between action and verbs was significant, $F(2,57)=16.20, p<.01, \eta_{\mathrm{p}}^{2}=.36, \mathrm{BF}_{10}=1.48^{+4}$. The analysis revealed no effect of verbs, $F(1,57)=0.02, p=$ $.88, \eta_{\mathrm{p}}^{2}=.001, \mathrm{BF}_{10}=0.19$. But there was a main effect

Table 9. Statistics according to the nature of the verbs (toward and away) and to the mode of response (pulling, pushing, and pressing)

\begin{tabular}{ccc}
\hline & Verbs toward & Verbs away \\
\hline Press-pull & $t(58)=5.57$, & $t(58)=3.00$, \\
& $P_{\text {holm }}<.001, \eta_{p}^{2}=.34$ & $P_{\text {holm }}=.01, \eta_{p}^{2}=.13$ \\
Press-push & $t(58)=3.43$, & $t(58)=5.00$, \\
& $P_{\text {holm }}=.005, \eta_{p}^{2}=.16$ & $P_{\text {holm }}<.001, \eta_{p}^{2}=.30$ \\
Pull-push & $t(58)=9.09$, & $t(58)=8.01$, \\
& $P_{\text {holm }}<.001, \eta_{p}^{2}=.58$ & $P_{\text {holm }}<.001, \eta_{p}^{2}=.52$ \\
\hline
\end{tabular}

of action, $F(2,57)=7.18, p<.01, \eta_{\mathrm{p}}^{2}=.08, \mathrm{BF}_{10}=3.79$. Comparisons showed that pressing induced less false recalls than pulling, $t(38)=3.58, p_{\mathrm{holm}}=.002, \eta_{\mathrm{p}}^{2}=.25$, and pushing, $t(38)=2.38, p_{\text {holm }}=.012, \eta_{\mathrm{p}}^{2}=.12$. But there was no difference between pulling and pushing, $t(38)=$ $0.71, p_{\text {holm }}=.477, \eta_{\mathrm{p}}^{2}=.01$. The post hoc analysis of the interaction (Table 9) showed that for verbs "toward," the pulling mode of response induced more false recalls than pressing and pushing, but no difference was found between pressing and pushing; for verbs "away," pushing produced more recalls than pulling and pushing, but no difference was found between pressing and pulling.

\section{Conclusion}

The results show a robust overlapping effect between the nature of the action performed and the category of the verb recalled. In other words, participants recalled more verbs "away from the body" after a pushing action and more verbs "toward the body" after a pulling action. Moreover, it should be noted that performing a pressing action did not induce the recall of a specific verb category and that performing an action incongruent with the movement associated with a verb resulted in lower levels of recall compared to performing a pressing action.

Even if the number of false recalls was low (i.e., maximum of three items per participant), the results highlighted that the action performed induced the production of nonlearned verbs for which the associated motor action was congruent with this action (i.e., pushing action induced production of "away" verbs, and pulling action induced the production of "toward" verbs). Interestingly, the action "press the keyboard" did not induce the production of a particular type of verb.

\section{General Discussion}

For a long time, the sensorimotor system was not considered as a contributing system in conceptual processing of words or sentences evoking an action. Over the last 20 years, behavioral and neuroimaging data suggested that the sensorimotor system is active during the processing of action words or sentences. However, the question is far from being definitely closed.

Among the researchers subscribing to the embodied cognition framework, there is a debate about the dependence of the conceptual system on the sensorimotor system (Dove, 2011; Meteyard et al., 2012; Michel, 2020; 
Wurm \& Caramazza, 2019). Researchers like Mahon and Caramazza (2008) consider that the activation of sensorimotor areas observed with neuroimagery is the consequence of conceptual activation (see also Mahon, 2015, response to Glenberg, 2015) while others (e.g., Barsalou, 2016) consider that the sensorimotor system is not enough to account for conceptual abstraction, though it can facilitate abstraction in some cases. Another view (e.g., Glenberg, 2015) considering the activation of sensorimotor areas gives rise to conceptual abstraction. Finally, the pluralist view proposed by Zwaan $(2014,2016)$ suggests that if the sensorimotor system contributes to the conceptual system, it cannot account for the entirety of the conceptual knowledge, as symbolic representations remain necessary.

As can be seen, the role of the sensorimotor system in representing conceptual knowledge is still under hot debate.

In the field of memory, the multiple traces memory models (e.g., MINERVA 2 - Hintzman, 1984, 1988; VISA - Whittlesea, 1989; Act-In - Versace et al., 2014; ATHENA - Briglia, et al., 2018) consider that the content of memory traces is closely related to former sensorimotor activities and that knowledge emerges when, in the current situation, some cues share various sensorimotor components of the memory traces. The aim of the present work was to test this assumption for action verbs by assessing how the congruence with the verb of an action performed at the stage of retrieval could influence memory performance, even when participants were not instructed to consider the action implied by the verb.

The results of the first experiment showed an overlap effect between the movement associated with the verbs to be recognized and the action performed to provide the memory judgment. Participants recognized verbs more often and more quickly with a consistent action than with an inconsistent action. Moreover, discriminating new verbs from old verbs was more difficult when the action to produce the answer was congruent with the action suggested by the verb presented.

The results of the second experiment also showed an overlap effect between the action performed, which was used as a cue for the recall, and the ability to recall the verbs learned. Thus, performing an action congruent with the motor action associated with a verb resulted in higher levels of recall compared to performing an action incongruent with the motor action associated with the verbs.

Moreover, in the two experiments, in comparison with a neutral action (i.e., pressing a key), the retrieval of learned verbs was higher when the action was consistent with the motor action associated with them and weaker when the action was not consistent. These results support the idea that the memory performances of the participants are the product of the overlap between the simulated motor action induced when reading a verb and the motor action performed to provide a judgment. The results observed on the nonlearned verbs (false alarms in Experiment 1) and on the verbs wrongly produced (false recalls in Experiment 2) also support this idea. Therefore, those results highlight an action-based memory effect at the retrieval stage.

The first interest of this work is to enrich the literature on the links already observed between action and memory. According to the "enactment paradigm," an item studied with an associated action is better memorized than an item studied only verbally (for review, see Zimmer et al., 2001). This finding was observed both in recall and recognition tasks, as well as when the action was performed at the time of encoding (e.g., Denis et al., 1991; Engelkamp et al., 1993; Knopf, 1991; Kubik et al., 2014; Lagacé \& Guérard, 2015; Mohr et al., 1989; Zimmer, 1991). However, there were some discussions on the power of enactment in situations where the action was only performed at the time of retrieval (e.g., Brooks \& Gardiner, 1994; Engelkamp et al., 1994; Kormi-Nouri et al., 1994; Mulligan \& Hornstein, 2003; Norris \& West, 1993). Our findings show an effect of the congruency of an action performed only at the stage of retrieval, after a verbal encoding task, in both recognition and recall tasks. Moreover, in contrast with previous studies, where participants were explicitly asked to perform the action associated with the item to be retrieved, in our experiments, the action is part of the experimental device, which means that participants did not focus on the action per se, but on the judgment to be made.

The second contribution of this work is that it supports the way in which memory recovery is conceived by multiple traces memory models. Indeed, it seems that, in our work, the feeling of memory emerges from the coupling between the present sensorimotor experience and the trace of past sensorimotor experiences associated to the verbs. As suggested by the ATHENA model (Briglia et al., 2018), what need to be memorized are the covariances (the notion of covariance is borrowed from O'Regan \& Noë, 2001) between the present sensorimotor information processing and past sensorimotor information processing. These covariances are sufficient to account for cognitive information (Hutto \& Myin, 2012) because if two processes are covariant, they are probably linked. Moreover, the intensity of the covariance (i.e., fluency) is a cue to infer the link between present and past information processing that will trigger the emergence of a feeling of pastness, which is then expressed in a memory judgment. In other words, this judgment would be modulated by the congruency generated by the overlapping between the motor programs associated with the action performed and the motor simulations associated with the verbs. Indeed, several works showed that motor compatibilities generate fluency (Beilock \& Holt, 2007; Brouillet 
et al., 2011; Cannon et al., 2010; Jasmin \& Casasanto, 2012; Yang et al., 2009) and motor fluency enhance memory (Brouillet et al., 2017).

Finally, the third interest of this work is associated with the value of $d^{\prime}$ (i.e., ability to discriminate old verbs and new verbs) in Experiment 1 and false recalls in experiment 2 (i.e., the production of new action verbs in accordance with the movement of the lever). Indeed, these can provide useful information on the mechanism at work at the recovery stage and, consequently, can contribute to the debate on the implication of the motor system in action verb processing. Overall, the results show that participants have more difficulty in discriminating old from new verbs when they move the lever than when they press a key on the keyboard. Moreover, this difficulty is higher when the action carried out with the lever is not congruent with the action associated with the verb. So, the action performed with the lever interferes with the access to memory traces. This suggests that it is the action performed with the lever that guides memory judgment by driving the activation of the sensorimotor dimensions associated with a verb. The false recalls in the second experiment support this interpretation. Thus, and in accordance with multitraces memory models, the coupling between the sensorimotor experiences would not be from past sensorimotor experiences to present sensorimotor experience but from present sensorimotor experience to past sensorimotor experiences. In other words, the present situation shapes what will be remembered, especially through the actions taken. In that way, memory is enacted (Brouillet, 2020).

We think that this finding could also be related with what is called "action reappraisal" by Federico and Brandimonte $(2019,2020)$ in the field of understanding tool use. In contrast with dominant conceptions (see Buxbaum, 2010), they consider that when agents have to use a tool they do not automatically activate the sensorimotor representations associated with the previous use of the tool, but first they reason about the "possibility to act" within a particular context and particular intention (see also Osiurak \& Badets, $2016,2017)$. Only in a second step, and according to what is needed, will the sensorimotor representations be activated. The paradigm called "technical reasoning hypothesis" has now received a significant number of experimental validations (Federico et al., 2021), even if it is still questionable (Osiurak et al., 2020).

All these findings suggest that the involvement of sensorimotor processes in knowledge is context-dependent. This has been well shown by Tousignant and Pexman (2012): Altering the task instructions given to participants changes the semantic information used to categorize words. Tousignant and Pexman (2012) compared the reaction times and accuracy in semantic decision for words that were high in body-object interaction (BOI) and for words low in
BOI according to the given instruction (i.e., "is it an entity or not" vs. "is it an action or not"). BOI assesses perceptions of the ease with which a human body can physically interact with a word's referent (Siakaluk, Pexman, Aguilera et al., 2008; Siakaluk, Pexman, Sears et al., 2008). When participants were told to judge entity, the semantic decision and reaction times were better for high BOI words than for low BOI words (the BOI effect). In contrast, when participants were told to judge action features, no BOI effect was observed. But the two intermediate conditions "entity vs. action" and "action vs. entity" showed moderate BOI effects. These results suggested that body-based semantic information might only be accessed when they are relevant to the task.

If it seems that the access to sensorimotor representation is context-dependent, this issue is also controversial. While Yee and Thompson-Schill (2016) consider that all semantic processing is driven by the context, Dove (2016) argues that this is not always the case.

Clearly, more researches are needed to clarify the role of sensorimotor processes in the processes underlying conceptual knowledge.

\section{References}

Andres, M., Finocchiaro, C., Buiatti, M., \& Piazza, M. (2015). Contribution of motor representations to action verb processing. Cognition, 134, 174-184. https://doi.org/10.1016/j.cognition.2014. 10.004

Aravena, P., Hurtado, E., Riveros, R., Cardona, J. F., Manes, F., \& Ibáñez, A. (2010). Applauding with closed hands: Neural signature of action-sentence compatibility effects. PLoS One, 5(7), e11751. https://doi.org/10.1371/journal.pone.0011751

Barsalou, L. W. (2010). Grounded cognition: Past, present, and future. Topics in Cognitive Science, 2(4), 716-724. https://doi. org/10.1111/j.1756-8765.2010.01115.x

Barsalou, L. W. (2016). Situated conceptualization: Theory and applications. In Y. Coello \& M. H. Fischer (Eds.), Foundations of embodied cognition: Perceptual and emotional embodiment (pp. 11-37). Routledge, Taylor \& Francis.

Beauprez, S. A., \& Bidet-Ildei, C. (2017). Perceiving a biological human movement facilitates action verb processing. Current Psychology: A Journal for Diverse Perspectives on Diverse Psychological Issues, 38(5), 1355-1359. https://doi.org/10.1007/ s12144-017-9694-5

Beilock, S. L., \& Holt, L. E. (2007). Embodied preference judgments: Can likeability be driven by the motor system? Psychological Science, 18(1), 51-57. https://doi.org/10.1111/j.1467-9280.2007.01848.x

Bidet-Ildei, C., Gimenes, M., Toussaint, L., Almecija, Y., \& Badets, A. (2017). Sentence plausibility influences the link between action words and the perception of biological human movements. Psychological Research, 81(4), 806-813. https://doi.org/10.1007/ s00426-016-0776-z

Borghi, A. M., \& Binkofski, F. (2014). Words as social tools: An embodied view on abstract concepts. Springer.

Boulenger, V., Hauk, O., \& Pulvermüller, F. (2009). Grasping ideas with the motor system: Semantic somatotopy in idiom 
comprehension. Cerebral cortex, 19(8), 1905-1914. https://doi. org/10.1093/cercor/bhn217

Briglia, J., Servajean, P., Michalland, A.-H., Brunel, L., \& Brouillet, D. (2018). Modeling an enactivist multiple-trace memory. Athena: A fractal model of human memory. Journal of Mathematical Psychology, 82, 97-110. https://doi.org/10.1016/j.jmp.2017.12.002

Brooks, B. M., \& Gardiner, J. M. (1994). Age differences in memory for prospective compared with retrospective subject-performed tasks. Memory \& Cognition, 22(1), 27-33. https://doi.org/10. 3758/BF03202758

Brouillet, D. (2019). Agir pour connaitre (act to know). Presses Universitaires de Grenoble.

Brouillet, D. (2020). Enactive memory. Frontiers in Psychology, 11, 114. https://doi.org/10.3389/fpsyg.2020.00114

Brouillet, D., Brouillet, T., Milhau, A., Heurley, L., Vagnot, C., \& Brunel, L. (2015). Word-to-picture recognition is a function of motor components mappings at the stage of retrieval. International Journal of Psychology, 51(5), 397-402. https://doi.org/ 10.1002/ijop.12210

Brouillet, D., Michalland, A., Guerineau, R., Thébault, G., \& Moruth, D. (2018). Are participants sensitive to the observation of an injured hand when they have to categorize an easily graspable object with their own hand? The Quarterly Journal of Experimental Psychology, 1(12), 1466-1477. https://doi.org/10.1177/ 1747021818801484

Brouillet, D., Milhau, A., Brouillet, T., \& Servajean, P. (2017). Effect of an unrelated fluent action on word recognition: A case of motor discrepancy. Psychonomic Bulletin \& Review, 24(3), 894-900. https://doi.org/10.3758/s13423-016-1160-0

Brouillet, D., \& Versace, R. (2019). The nature of the traces and the dynamics of memory. Psychology and Behavioral Sciences, 8(6), 151-157. https://doi.org/10.11648/j.pbs.20190806.12

Brouillet, T., Ferrier, L. P., Grosselin, A., \& Brouillet, D (2011). Action compatibility effects are hedonically marked and have incidental consequences on affective judgment. Emotion, 11(5), 1202. https://doi.org/10.1037/a0024742

Brouillet, T., Heurley, L., Martin, S., \& Brouillet, D. (2010). The embodied cognition theory and the motor component of "yes" and "no" verbal responses. Acta Psychologica, 134(3), 310-317. https://doi.org/10.1016/j.actpsy.2010.03.003

Buxbaum, L. J. (2010). Ideomotor apraxia: A call to action. Neurocase, 7(6), 445-458. https://doi.org/10.1093/neucas/7.6.445

Canits, I., Pecher, D., \& Zeelenberg, R. (2018). Effects of grasp compatibility on long-term memory for objects. Acta psychologica, 182, 65-74. https://doi.org/10.1016/j.actpsy.2017.11.009

Cannon, P. R., Hayes, A. E., \& Tipper, S. P. (2010). Sensorimotor fluency influences affect: Evidence from electromyography. Cognition \& Emotion, 24(4), 681-691. https://doi.org/10.1080/ 02699930902927698

De Vega, M., Glenberg, A., \& Graesser, A (2012). Symbols and embodiment: Debates on meaning and cognition. Oxford University Press.

Denis, M., Engelkamp, J., \& Mohr, G. (1991). Memory of imagined actions: Imagining oneself or another person. Psychological Research, 53(3), 246-250. https://doi.org/10.1007/BF00941394

Dove, G. (2011). On the need for embodied and dis-embodied cognition. Frontiers Psychology, 1, 242. https://doi.org//10. 3389/fpsyg.2010.00242

Dove, G. (2016). Three symbol ungrounding problems: Abstract concepts and the future of embodied cognition. Psychonomic Bulletin \& Review, 23(4), 1109-1121. https://doi.org/10.3758/ s13423-015-0825-4

Duscherer, K., \& Mounoud, P. (2006). Normes d'associations verbales pour 151 verbes d'action. L'Année Psychologique, 106(3), 397-413. https://doi.org/10.4074/S0003503306003046
Dutriaux, L., Dahiez, X., \& Gyselinck, V. (2019). How to change your memory of an object with a posture and a verb. Quarterly Journal of Experimental Psychology, 72(5), 1112-1118. https://doi.org/10. $1177 / 1747021818785096$

Engelkamp, J. (1998). Memory for actions [Google Scholar]. Psychology Press.

Engelkamp, J., Zimmer, H. D., \& Biegelmann, U. E. (1993). Bizarreness effects in verbal tasks and subject-performed tasks. European Journal of Cognitive Psychology, 5(4), 393-415. https:// doi.org/10.1080/09541449308520127

Engelkamp, J., Zimmer, H. D., Mohr, G., \& Sellen, O. (1994). Memory of self-performed tasks: Self-performing during recognition. Memory \& Cognition, 22(1), 34-39. https://doi.org/10.3758/ BF03202759

Faul, F., Erdfelder, E., Lang, A.-G., \& Buchner, A. (2007). G*Power 3: A flexible statistical power analysis program for the social, behavioral, and biomedical sciences. Behavior Research Methods, 39(2), 175-191. https://doi.org/10.3758/ BF03193146

Federico, G., \& Brandimonte, M. A. (2019). Tool and object affordances: An ecological eye-tracking study. Brain and cognition, 135, 103582. https://doi.org/10.1016/j.bandc.2019.103582

Federico, G., \& Brandimonte, M. A. (2020). Looking to recognise: The pre-eminence of semantic over sensorimotor processing in human tool use. Scientific Reports, 10(1), 1-16. https://doi.org/10. 1038/s41598-020-63045-0

Federico, G., Osiurak, F., \& Brandimonte, M. A. (2021). Hazardous tools: The emergence of reasoning in human tool use. Psychological Research, 1-11. https://doi.org/10.1007/s00426-020-01466-2

Fincher-Kiefer, R. (2019). How the body shapes knowledge: Empirical support for embodied cognition. American Psychological Association.

Fischer, M. H., \& Coello, Y. (2015). Conceptual and interactive embodiment: Foundations of embodied cognition (Vol. 2). Taylor \& Francis.

Fischer, M. H., \& Coello, Y. E. (2016). Foundations of embodied cognition: Conceptual and interactive embodiment. Routledge, Taylor \& Francis.

Gimenez, C., \& Brouillet, D. (2020). The role of the motor system in visual working memory. Cognition, Brain and Behavior, XXIV(2), 153-162. https://doi.org/10.24193/cbb.2020.24.09

Glenberg, A. M. (2015). Few believe the world is flat: How embodiment is changing the scientific understanding of cognition. Canadian Journal of Experimental Psychology, 69(2),165-171. https://doi.org/10.1037/cep0000056

Glenberg, A. M., \& Kaschak, M. P. (2002). Grounding language in action. Psychonomic Bulletin \& Review, 9(3), 558-565. https:// doi.org/10.3758/BF03196313

Green, D. M., \& Swets, J. A. (1966). Signal detection theory and psychophysics (Vol. 1). Wiley.

Hintzman, D. L. (1988). Judgments of frequency and recognition memory in a multiple-trace memory model. Psychological Review, 95(4), 528. https://doi.org/10.1037/0033-295X.95.4.528

Hintzman, D. L. (1984). Minerva 2: A simulation model of human memory. Behavior Research Methods, Instruments, \& Computers, 16(2), 96-101. https://doi.org/10.3758/BF03202365

Hutto, D., \& Myin, E (2012). Radicalizing enactivism: Basic minds without content. Mit Press.

Jasmin, K., \& Casasanto, D. (2012). The QWERTY Effect: How typing shapes the meanings of words. Psychonomic Bulletin \& Review, 19(3), 499-504. https://doi.org/10.3758/s13423-0120229-7

Knopf, M. (1991). Having shaved a kiwi fruit: Memory of unfamiliar subject-performed actions. Psychological Research, 53(3), 203-211. https://doi.org/10.1007/BF00941388 
Koriat, A., Goldsmith, M., \& Pansky, A. (2000). Toward a psychology of memory accuracy. Annual Review of Psychology, 51(1), 481-537. https://doi.org/10.1146/annurev.psych.51.1.481

Kormi-Nouri, R., Nyberg, L., \& Nilsson, L.-G. (1994). The effect of retrieval enactment on recall of subject-performed tasks and verbal tasks. Memory \& Cognition, 22(6), 723-728. https://doi. org/10.3758/BF03209257

Kubik, V., Obermeyer, S., Meier, J., \& Knopf, M. (2014). The enactment effect in a multi-trial free-recall paradigm. Journal of Cognitive Psychology, 26(7), 781-787. https://doi.org/10.1080/ 20445911.2014.959018

Lagacé, S., \& Guérard, K. (2015). When motor congruency modulates immediate memory for objects. Acta Psychologica, 157, 65-73. https://doi.org/10.1016/j.actpsy.2015.02.009

Liepelt, R., Dolk, T., \& Prinz, W. (2012). Bidirectional semantic interference between action and speech. Psychological Research, 76(4), 446-455. https://doi.org/10.1007/s00426-011-0390-z

Mahon, B. Z., \& Caramazza, A. (2008). A critical look at the embodied cognition hypothesis and a new proposal for grounding conceptual content. Journal of Physiology, Paris, 102(1-3), 59-70. https://doi.org//10.1016/j.jphysparis.2008.03.004

Mahon, B. Z. (2015). Response to Glenberg: Conceptual content does not constrain the representational format of concepts. Canadian Journal of Experimental Psychology/Revue canadienne de psychologie expérimentale, 69(2), 179-180. https://doi. org/10.1037/cep0000059

Mecklinger, A., Gruenewald, C., Weiskopf, N., \& Doeller, C. F. (2004). Motor affordance and its role for visual working memory: Evidence from fMRI studies. Experimental Psychology, 51(4), 258-269. https://doi.org/10.1027/1618-3169.51.4.258

Meteyard, L., Cuadrado, S. R., Bahrami, B., \& Vigliocco, G. (2012). Coming of age: A review of embodiment and the neuroscience of semantics. Cortex, 48(7), 788-804. https://doi.org/10.1016/j. cortex.2010.11.002

Michel, C. (2020). Overcoming the modal/amodal dichotomy of concepts. Phenomenology and Cognitive Sciences. https://doi. org/10.1007/s11097-020-09678-y

Miller, J., Brookie, K., Wales, S., Wallace, S., \& Kaup, B. (2018). Embodied cognition: Is activation of the motor cortex essential for understanding action verbs? Journal of Experimental Psychology: Learning, Memory, and Cognition, 44(3), 335-370. https://doi.org/10.1037/xlm0000451

Mohr, G., Engelkamp, J., \& Zimmer, H. D. (1989). Recall and recognition of self-performed acts. Psychological Research, 51(4), 181-187. https://doi.org/10.1007/BF00309146

Montero-Melis, G., van Paridon, J., Ostarek, M., \& Bylund, E. (2019). Does the motor system functionally contribute to keeping words in working memory? A pre-registered replication of Shebani and Pulvermüller (2013, Cortex). PsyArXiv. https://doi.org/10.31234/ osf.io/pqf8k

Mulligan, N. W., \& Hornstein, S. L. (2003). Memory for actions: Selfperformed tasks and the reenactment effect. Memory \& Cognition, 31(3), 412-421. https://doi.org/10.3758/BF03194399

Norris, M. P., \& West, R. L. (1993). Activity memory and aging: The role of motor retrieval and strategic processing. Psychology and Aging, 81(1), 81-86. https://doi.org/10.1037/0882-7974.8.1.81

O'Regan, J. K., \& Noë, A. (2001). A sensorimotor account of vision and visual consciousness. Behavioral and Brain Sciences, 24(5), 939-1031. https://doi.org/10.1017/S0140525X01000115

Osiurak, F., \& Badets, A. (2016). Tool use and affordance: Manipulationbased versus reasoning-based approaches. Psychological Review, 123(5), 534. https://doi.org/10.1037/rev0000027

Osiurak, F., \& Badets, A. (2017). Use of tools and misuse of embodied cognition: Reply to Buxbaum (2017). Psychological Review, 124(3), 361-368. https://doi.org/10.1037/rev0000065
Osiurak, F., Federico, G., Brandimonte, M. A., Reynaud, E., \& Lesourd, M. (2020). On the temporal dynamics of tool use. Frontiers in Human Neuroscience, 14, 579378. https://doi.org/10. 3389/fnhum.2020.579378

Pecher, D., de Klerk, R. M., Klever, L., Post, S., van Reenen, J. G., \& Vonk, M. (2013). The role of affordances for working memory for objects. Journal of Cognitive Psychology, 25(1), 107-118. https:// doi.org/10.1080/20445911.2012.750324

Pecher, D. (2013). No role for motor affordances in visual working memory. Journal of Experimental Psychology: Learning, Memory, and Cognition, 39(1), 2-13. https://doi.org/10.1037/a0028642

Pecher, D., \& Zwaan, R. A (2005). Grounding cognition: The role of perception and action in memory, language, and thinking. Cambridge University Press.

Pulvermüller, F., \& Fadiga, L. (2010). Active perception: Sensorimotor circuits as a cortical basis for language. Nature Reviews Neuroscience, 11(5), 351-360. https://doi.org/10.1038/nrn2811

Pulvermüller, F., Shtyrov, Y., \& Ilmoniemi, R. (2005). Brain signatures of meaning access in action word recognition. Journal of Cognitive Neuroscience, 17(6), 884-892. https://doi.org/10.1162/ 0898929054021111

Quak, M., Pecher, D., \& Zeelenberg, R. (2014). Effects of motor congruence on visual working memory. Attention, Perception, \& Psychophysics, 76(7), 2063-2070. https://doi.org/10.3758/ s13414-014-0654-y

Richardson, D. C., Spivey, M. J., \& Cheung, J. (2001). Motor representations in memory and mental models: The embodied zork. Proceedings of the 23rd Annual Meeting of the Cognitive Science Society (pp. 867-872). http://conferences.inf.ed.ac. uk/cogsci2001/pdf-files/0839.pdf

Rouder, J. N., Speckman, P. L., Sun, D., Morey, R. D., \& Iverson, G. (2009). Bayesian $t$ tests for accepting and rejecting the null hypothesis. Psychonomic Bulletin \& Review, 16(2), 225-237. https://doi.org/10.3758/PBR.16.2.225

Schneider, W., Eschman, A., \& Zuccolotto, A. (2012). E-Prime: User's guide. Pittsburgh Psychology Software Tool Inc. https://lyrawww. uvt.nl/ cenv/dci-lab/e-prime/GettingStartedGuide.pdf

Schönbrodt, F. D., \& Wagenmakers, E.-J. (2018). Bayes factor design analysis: Planning for compelling evidence. Psychonomic Bulletin \& Review, 25(1), 128-142. https://doi.org/10.3758/s13423017-1230-y

Shapiro, L. (2019). Embodied cognition. Routledge, Taylor \& Francis. Shapiro, L. (2014). The Routledge handbook of embodied cognition. Routledge, Taylor \& Francis.

Shebani, Z., \& Pulvermüller, F. (2013). Moving the hands and feet specifically impairs working memory for arm- and leg-related action words. Cortex, 49(1), 222-231. https://doi.org/10.1016/j. cortex.2011.10.005

Siakaluk, P. D., Pexman, P. M., Aguilera, L., Owen, W. J., \& Sears, C. R. (2008). Evidence for the activation of sensorimotor information during visual word recognition: The body-object interaction effect. Cognition, 106(1), 433-443. https://doi.org/10.1016/ j.cognition.2006.12.011

Siakaluk, P. D., Pexman, P. M., Sears, C. R., Wilson, K., Locheed, K., \& Owen, W. J. (2008b). The benefits of sensorimotor knowledge: Body-object interaction facilitates semantic processing. Cognitive Science, 32(3), 591-605. https://doi.org/10.1080/ 03640210802035399

Springer, A., \& Prinz, W. (2010). Action semantics modulate action prediction. The Quarterly Journal of Experimental Psychology, 63(11), 2141-2158. https://doi.org/10.1080/17470211003721659

Tousignant, C., \& Pexman, P. M. (2012). Flexible recruitment of semantic richness: Context modulates body-object interaction effects in lexical-semantic processing. Frontiers in Human Neuroscience, 6, 53. https://doi.org/10.3389/fnhum.2012.00053 
Tulving, E. (1976). Ecphoric processes in recall and recognition. In J. Brown (Ed.), Recall and recognition. (pp. 37-73). Wiley.

Tulving, E. (1982). Synergistic ecphory in recall and recognition. Canadian Journal of Psychology/Revue canadienne de psychologie, 36(2), 130-147. https://doi.org/10.1037/h0080641

van Dam, W. O., Rueschemeyer, S. A., Bekkering, H., \& Lindemann, O. (2013). Embodied grounding of memory: Toward the effects of motor execution on memory consolidation. The Quarterly Journal of Experimental Psychology, 66(12), 2310-2328. https:// doi.org/10.1080/17470218.2013.777084

van Elk, M., van Schie, H. T., Zwaan, R. A., \& Bekkering, H. (2010). The functional role of motor activation in language processing: Motor cortical oscillations support lexical-semantic retrieval. Neuroimage, 50(2), 665-677. https://doi.org/10.1016/j.neuroimage.2009.12.123

Versace, R., Vallet, G. T., Riou, B., Lesourd, M., Labeye, É., \& Brunel, L. (2014). Act-In: An integrated view of memory mechanisms. Journal of Cognitive Psychology, 26(3), 280-306. https://doi.org/ 10.1080/20445911.2014.892113

Vitale, F., Padrón, I., Avenanti, A., \& de Vega, M. (2020). Enhancing motor brain activity improves memory for action language: $A$ tDCS study. Cerebral Cortex, 31(3), 1569-1581. https://doi.org/10. 1093/cercor/bhaa309

Wagenmakers, E.-J., Love, J., Marsman, M., Jamil, T., Ly, A., Verhagen, J., Selker, R., Gronau, Q. F., Dropmann, D., Boutin, B., Meerhoff, F., Knight, P., Raj, A., van Kesteren van, E.-J., van Doorn van, J., Šmíra, M., Epskamp, S., Etz, A., ..., Morey, R. D. (2018). Bayesian inference for psychology. Part II: Example applications with JASP. Psychonomic Bulletin and Review, 25(1), 58-76. https://doi.org/10.3758/s13423-017-1323-7

Wagenmakers, E.-J., Marsman, M., Jamil, T., Ly, A., Verhagen, J., Love, J., Selker, R., Gronau, Q. F., Šmíra, M., Epskamp, S., Matzke, D., Rouder, J. N., \& Morey, R. D. (2018). Bayesian inference for psychology. Part I: Theoretical advantages and practical ramifications. Psychonomic Bulletin and Review, 25(1), 35-57. https://doi.org/10.3758/s13423-017-1343-3

Whittlesea, B. W. (1989). Selective attention, variable processing, and distributed representation: Preserving particular experiences of general structures. In R. G. M. Morris. (Ed.). Parallel distributed processing: Implications for psychology and neurobiology (pp. 76-101). Clarendon Press/Oxford University Press. https://books.google.fr/books/about/Parallel_Distributed_ Processing.html?id=4rx9AAAAMAAJ\&redir_esc $=y$

Willems, R. M., Hagoort, P., \& Casasanto, D. (2010). Body-specific representations of action verbs neural evidence from right- and left-handers. Psychological Science, 21(1), 67-74. https://doi. org/10.1177/0956797609354072

Willems, R. M., Labruna, L., D’Esposito, M., Ivry, R., \& Casasanto, D. (2011). A functional role for the motor system in language understanding evidence from theta-burst transcranial magnetic stimulation. Psychological Science, 22(7), 849-854. https://doi. org/10.1177/0956797611412387

Wurm, M. F., \& Caramazza, A. (2019). Distinct roles of temporal and frontoparietal cortex in representing actions across vision and language. Nature Communications, 10(1), 1-10. https://doi.org/ 10.1038/s41467-018-08084-y

Yang, S. J., Gallo, D. A., \& Beilock, S. L. (2009). Embodied memory judgments: A case of motor fluency. Journal of Experimental Psychology: Learning, Memory, and Cognition, 35(5), 1359. https://doi.org/10.1037/a0016547

Yee, E., \& Thompson-Schill, S. L. (2016). Putting concepts into context. Psychonomic Bulletin \& Review, 23(4), 1015-1027. https://doi.org/10.3758/s13423-015-0948-7

Zeelenberg, R., \& Pecher, D. (2016). The role of motor action in memory for objects and words. In B. H. Ross (Ed.), Psychology of learning and motivation (Vol. 64, pp. 161-193). Academic Press.

Zimmer, H. D., Cohen, R. L., Guynn, M. J., Engelkamp, J., KormiNouri, R., \& Foley, M. A (2001). Memory for Action: A Distinct Form of Episodic Memory? Oxford University Press. https://global. oup.com/academic/product/memory-for-action

Zimmer, H. D. (1991). Memory after motoric encoding in a generation-recognition model. Psychological Research, 53(3), 226-231. https://doi.org/10.1007/BF00941391

Zwaan, R. A. (2014). Embodiment and language comprehension: Reframing the discussion. Trends in Cognitive Sciences, 18(5), 229-234. https://doi.org/10.1016/j.tics.2014.02.008

Zwaan, R. A. (2016). Situation models, mental simulations, and abstract concepts in discourse comprehension. Psychonomic Bulletin \& Review, 23(4), 1028-1034. https://doi.org/10.3758/ s13423-015-0864-x

\section{History}

Received September 1, 2020

Revision received February 27, 2021

Accepted March 19, 2021

Published online June 10, 2021

\section{Publication Ethics}

All participants gave their informed consent to take part in this experiment and signed the Laboratory's Charter of Ethics.

\section{Open Data}

Results of Experiments 1 and 2 are openly available at the following link: https://osf.io/anzg6/?view_only=8b30468ed3e041f3a854586 9c5669234

\section{ORCID}

Thibaut Brouillet

(D) https://orcid.org/0000-0001-6734-3188

\section{Thibaut Brouillet}

CERSM Laboratory (EA 2931)

Université Paris Nanterre

200 Avenue de la République

92000 Nanterre

France

thibaut.brouillet@gmail.com 


\section{Appendix}

Characteristics of the 32 Verbs Selected: MA,

C (max. 7), LF, NL

Table A1. Verbs implying action away from the body

\begin{tabular}{|c|c|c|c|c|}
\hline & $\% M A$ & C & LF & $\mathrm{NL}$ \\
\hline Appuyer (press) & 100 & 6 & 16.49 & 7 \\
\hline Donner (give) & 100 & 5.4 & 216.55 & 6 \\
\hline Ecarter (dismiss) & 99 & 4.85 & 16.89 & 7 \\
\hline Eloigner (move away) & 99 & 5.7 & 28.45 & 8 \\
\hline Epandre (spread) & 100 & 6 & 0.41 & 7 \\
\hline Expulser (expel) & 100 & 5.2 & 23 & 8 \\
\hline Frapper (hit) & 100 & 4.8 & 32.09 & 6 \\
\hline Jeter (cast) & 100 & 6 & 61.89 & 5 \\
\hline Lancer (throw) & 100 & 6 & 26.08 & 6 \\
\hline Offrir (offer) & 98 & 4.71 & 50.34 & 6 \\
\hline Planter (plant) & 98 & 5.3 & 12.16 & 7 \\
\hline Pousser (push) & 100 & 6 & 45.58 & 7 \\
\hline Poser (place) & 100 & 4.6 & 73.85 & 5 \\
\hline Semer (sow) & 99 & 4.6 & 5.07 & 5 \\
\hline Verser (pour) & 98 & 5.97 & 9.86 & 6 \\
\hline Vider (empty) & 99 & 4.88 & 16.82 & 5 \\
\hline$M$ & 99.37 & 5.37 & 39.72 & 6. \\
\hline
\end{tabular}

Note. $\mathrm{C}=$ certainty of the judgment (max. 7); LF = lexical frequency (per million); $\mathrm{MA}=$ movement associated; $\mathrm{NL}=$ number of letters.
Table A2. Verbs implying action toward the body

\begin{tabular}{lcccc}
\hline & \% MA & C & LF & NL \\
\hline Arracher (snatch) & 100 & 5.8 & 34.32 & 8 \\
Aspirer (vacuum) & 92 & 5.01 & 3.92 & 7 \\
Attirer (attract) & 98 & 4.33 & 17.43 & 7 \\
Enfiler (thread) & 89 & 4.35 & 10.95 & 8 \\
Extraire (extract) & 90 & 5.12 & 5.68 & 8 \\
Hisser (hoist) & 100 & 5.96 & 6.2 & 6 \\
Mettre (put) & 88 & 4.23 & 230 & 6 \\
Oter (remove) & 89 & 5.02 & 10 & 4 \\
Puiser (draw) & 87 & 4.88 & 3.51 & 6 \\
Ramasser (pick up) & 90 & 5.02 & 17.2 & 8 \\
Ramener (bring) & 97 & 5.23 & 24.9 & 7 \\
Remonter (reassemble) & 90 & 5.16 & 38.51 & 8 \\
Rateler (rake) & 88 & 5.01 & 0.21 & 7 \\
Relever (raise) & 85 & 4.66 & 24.39 & 7 \\
Soulever (lift) & 91 & 4.84 & 17.16 & 8 \\
Tirer (pull) & 100 & 5.8 & 99.76 & 5 \\
Mean & 92.12 & 5.02 & 34 & 6.87 \\
\hline Note. C = certainty of the judgment (max. 7); LF = lexical frequency (per \\
million); MA = movement associated; NL = number of letters.
\end{tabular}

